\title{
ИСТОРИЯ
}

\author{
АКУЛЕНКО Вадим Сергеевич \\ канд. ист. наук, старший преподаватель кафедры корееведения Восточного \\ института - Школы региональных и международных исследований ДВФУ (г. Владивосток) \\ Электронная почта: akulenko.vs@dvfu.ru
}

\section{«Хвандан Коги» и проблема фальсификации истории в Республике Корея}

УДК 94(519)

\section{Хвандан коги, История Кореи, псевдоистория, неофициальная история, фальсификация истории, \\ Древняя Корея, Древний Чосон}

This work was supported by the Core University Program for Korean Studies through the Ministry of Education of the Republic of the Korea and Korean Studies Promotion Service of the Academy of Korean Studies (AKS-2015OLU-2250003)

\section{Для ицитирования:}

Акуленко В. С. «Хвандан Коги» и проблема фальсификации истории в Республике Корея // Известия Восточного института. 2020. № 3 . C. 6-14. doi: dx.doi. org/10.24866/2542-1611/2020 3/6-14 doi: dx.doi.org/10.24866/2542-1611/2020-3/6-14

Статья посвящена изучению проблемы фальсификации истории в Республике Корея с использованием сфабрикованных источников, ярким примером которых является «Хвандан коги». В качестве источниковой базы исследования выступило сочинение «Хвандан коги», а также материалы сайтов Международного научного общества Хвандан и новой корейской религии Чынсандо. Кроме того, автором был проанализирован ряд научных статей на русском, английском и корейском языках.

История Кореи в XX в. полна драматических событий. Несмотря на это именно в XX в. корейцы в полной мере ощутили себя отдельной нацией, что проявилось в том числе в росте интереса к национальному языку, истории и культуре. Вместе с тем у части крайне националистически настроенных корейцев этот интерес принял гипертрофированные формы и трансформировался в настойчивое желание найти в истории корейского народа «великое героическое прошлое», что породило целый ряд фальсификаций, часть которых базируется на признанном подделкой сочинении «Хвандан коги».

Актуальность настоящей работы состоит в необходимости широкого освещения проблемы фальсификации истории Кореи в отечественной историографии, так как в последние годы южнокорейские псевдоисторики настойчиво навязывают сотрудничество целому ряду российских академических организаций, что угрожает репутационными потерями и общему ухудшению имиджа российской науки не только в Республике Корея, но и в мире.

Цель данной работы заключается в освящении проблемы фальсификации истории с использованием недостоверных или сфальсифицированных источников, ярким примером которых является сочинение «Хвандан коги».

В качестве источниковой базы исследования использованы две опубликованные версии «Хвандан коги», которые были напечатаны в разные годы с комментариями от составителей и переводчиков [5, 17]. Кроме этого, был проанализирован ряд научных статей и публикаций на русском, английском и корейском языках, посвящённых вопросу создания и распространения «Хвандан коги». В работе также были использованы материалы сайтов Международного научного общества 
Хвандан [9], занимающегося популяризацией «Хвандан коги» и новой корейской религии Чынсандо [18], чей патриарх принимает большое участие в деле популяризации данного сочинения.

Проблема фальсификации фактов истории оказалась в центре общественного дискурса в РФ сравнительно недавно - в конце 2000-х гг. Однако в мире данный вопрос поднимается уже не одно десятилетие. Прежде чем перейти к рассмотрению проблемы фальсификации истории необходимо ответить на вопрос, что является фальсификацией истории?

В большом толковом словаре русского языка термин «фальсификация» (от лат. Falcificare - подделывать) обозначает подделку чеголибо, то есть сознательное искажение, подмену настоящего ложным с целью какой-либо выгоды [1, с. 1415]. Таким образом, под фальсификацией истории можно понимать сознательное искажение истории путём заведомо ложной трактовки исторических фактов, либо использования заведомо ложных фактов с целью извлечения из этого какой-либо выгоды.

Фальсификацию истории ни в коем случае не стоит путать с недостоверным изложением того или иного исторического события, которое в большинстве случаев имеет объективные причины [3, с. 366]. В этой связи в данной работе основное внимание будет уделено фальсификации истории Кореи, основанной на использовании заведомо ложных фактов, почерпнутых из сфальсифицированного исторического документа. Фальсификацией истории Кореи в таком виде в РК занимается целая группа лиц, которую в южнокорейской академической среде принято называть «неофициальными историками» ${ }^{1}$ или «псевдоисториками».

Впервые термин «неофициальная история» (재야사학, 在野史 學) в отношении к современным исследователям истории Кореи был применён на страницах газеты «Кёнхян синмун» [14] в ноябре 1978 г. Однако стоит отметить, что им также называют существовавшую в феодальной Корее XI - XIII вв. традицию неофициального историописания, когда наряду с официальной конфуцианской версией национальной истории существовал жанр буддийских исторических сочинений. Однако в XX в. данный термин обретает новый смысл. С конца 1970-х гг. им стали называть историков, которые не входили в университетское сообщество, избегали участия в научных мероприятиях, но при этом разрабатывали альтернативные концепции древней истории Кореи, сильно отличавшиеся от принятых в исторической науке.

В 1970-е - начале 1980-х гг. такие исследователи оформляются в отдельную группу, сплотившуюся вокруг движения за ревизию школьных учебников истории и опубликованного Комитетом по составлению национальной истории многотомника «История Кореи» [20]. Именно эта группа начинает прилагать значительные усилия для популяризации сочинения «Хвандан коги» (환단고기, 桓檀古記), которое признано подделкой как южнокорейской, так и северокорейской академической наукой.

Впервые сочинение «Хвандан коги», название которого на русский язык можно перевести, как «Древние записи [о временах царства] Хван[гук] и Тан[гуна]», была опубликовано в количестве 100 копий в 1979 г. издательством «Кваноихэса» и имело ряд недостатков, которые эксперты склонны считать признаком фальсификации. Поэтому не удивительно, что Ли Юрип - человек, которому большинство исследователей приписывают создание данного сочинения, ут-
1 От термина «неофициальная история» (재야사 학, 在野史學). 
верждал, что издание было осуществлено без его ведома. Косвенным доказательством этого предположения служит тот факт, что в следующем тираже «Хвандан коги», напечатанном в 1983 г. в издательстве «Пэдальыйсук», годом публикации значится 1979 г. Возможно, таким способом Ли Юрип пытался навсегда «похоронить» первую неудачную версию, которая тем не менее имела большой успех и уже в 1982 г. была переведена и опубликована в Японии. Чуть позже, в 1986 г., вышел перевод летописи и на современный корейский язык, после чего книга стала известна широкой общественности и завоевала популярность среди рядовых южнокорейских читателей [15].

Стоит также отметить, что отдельные его фрагменты публиковались и ранее. Например, в сочинении Ан Дончжуна и Им Сынгука 1978 г. «Мнение о древней истории Кореи» (한국고대사학관견) [11] или в статьях Ли Юрипа, опубликованных в ежемесячнике «Свобода» (자유) во второй половине 1970-х гг.

Подлинность летописи «Хвандан коги» была поставлена под сомнение практически сразу после её первой полной публикации в 1979 г., а в середине 1980-х гг. южнокорейские историки доказали, что она была сфальсифицирована. Первым с критикой «Хвандан коги» выступил в 1986 г. Ли Дохак [15].

Между тем авторство «летописи» её почитателями традиционно приписывается некому Ке Ёнсу, который якобы составил её из пяти различных документов и издал в количестве 30 копий в 1911 г. Одна из копий, по мнению псевдоисториков, и попала в руки Ли Юрипу. При этом версия, опубликованная в 1979 г., была якобы восстановлена и написана Ли Юрипом по памяти, так как подлинник летописи был к тому времени утрачен.

Таким образом, перед нами источник, подлинность которого проверить с использованием традиционных методов экспертизы источника весьма сложно (если вообе возможно), так как подлинник утрачен, а о его содержании мы можем судить только со слов его якобы последнего обладателя.

«Хвандан коги» в том виде, в котором оно предстало своим первым читателям в конце 1970-х - начале 1980-х гг., состоит из пяти частей: Самсонги (2 тома) (Записки трёх мудрецов), Тангунсэги (Летопись эры Тангуна), Пукпуёги (Летопись Северного Пуё) и Тхэбэгильса (Неофициальная история Тхэбэк). В Самсонги рассказывается о существовании так называемой страны Хвангук (существование не доказано), в Тангунсэги повествуется о 47 правителях династии Тангун, правивших в Древнем Чосоне (? - 108 г. до н. э.), в Пукпуёги представлен период после исчезновения Древнего Чосона и до образования Когурё (37 г. до н. э. - 668 г.), а Тхэбэгильса объединяет в себе записи об обширном периоде начиная с эпохи Хвангук и до существования государства Корё (918 - 1392 гг.) [5].

Изданию книги предшествовало создание в 1975 г. «Совета по поиску государственной истории» (국사찾기 협의회). Помимо Ли Юрипа, который подозревается в авторстве «Хвандан коги», в него вошли Пак Чханам, Ан Хосан, Ю Бонён, Мун Чончхан, Им Сынгук и другие. Главной целью нового общества было объявлено изучение «Хвандан коги», а также проведение раскопок и экспедиций с целью подтверждения достоверности этого источника [15]. 
Начиная с 1976 г. участники совета непрерывно критикуют представителей официальной исторической школы, в том числе через печатный орган общества - журнал «Свобода» [15]. А в 1978 г. Ан Хосан даже подаёт на имя президента, премьер-министра и министра культуры и образования РК докладную записку о необходимости исправить содержание школьного учебника истории и многотомника «История Кореи». Этот документ подписали ещё 8 членов совета.

Основное содержание докладной записки можно свести к следующему:

1) территория Древнего Чосона распространялась в северо-восточном направлении вплоть до морского побережья, на север - до реки Амур, а на запад - до Пекина;

2) необходимо вернуть в учебники 1200 лет эры Тангуна;

3) признать Тангуна реальной личностью;

4) перестать называть выходца из царства Янь - Ви Мана - основателем Чосона;

5) Вангомсон - столица Чосона Ви Мана - находилась около Шаньхайгуаньского прохода;

6) округ Лолан находился в районе Пекина;

7) Пэкче в течение 400 лет управляла южной частью центрального Китая;

8) после объединения Трёх государств королевством Силла в течение 68 лет его территория распространялась от китайского Цзилиня до Пекина [13, с. 12-13].

Таким образом, в своеобразном манифесте оппозиционной исторической школы можно увидеть глубокие расхождения со сложившимися на тот момент взглядами на древнюю историю Кореи, выработанными южнокорейской академической наукой [16].

Каким же образом люди, не имеющие отношения к академической науке, смогли быть услышаны на правительственном уровне? Ответ на этот вопрос кроется в личности человека, от имени которого был подан своеобразный манифест «оппозиционеров». Дело в том, что Ан Хосан являлся достаточно заметной политической фигурой в РК. К примеру, с 1948 по 1950 гг. он занимал должность министра культуры и образования РК и отвечал за создание антикоммунистической идеологии в правительстве Ли Сынмана. Он также известен как ярый последователь религии Тэчжонгё (대종교, 大倧呚), ставший её патриархом (총전교) с 1992 по 1997 г. [12].

Стоит ли после этого удивляться, что представители неофициальной исторической школы получили возможность отстаивать свою точку зрения на уровне парламентской комиссии и даже добились частичного удовлетворения своих требований о внесении изменений в официальную трактовку древней истории Кореи.

Популярность неофициальных историков в широкой обывательской среде и покровительство на самом высоком уровне позволило им выступить с ответной критикой в адрес академических историков, обвинив их в консерватизме и продвижении так называемого «колониального мировоззрения» (식민사관) ${ }^{2}$. Впрочем, эта критика имеет достаточно выборочный характер. К примеру, в своих работах они часто цитируют Чхве Намсона, автора теории о пульхамской культуpe, который как раз активно сотрудничал с японцами в колониаль-
2 Дословный перевод «колониальное восприятие истории». 
3 Согласно мифу о Тангуне, его отцом был сын небесного бога Хванина Хванун.

${ }^{4}$ Северо-восточным проектом в РК называют пятилетнюю «Серию исследовательских проектов по изучению истории и современного состояния северовосточной приграничной территории» (东北边疆历 史与现状系列研 究工程) Академии общественных наук КНР, реализация которого началась в 2002 г. Его основная цель - укрепле ние единства КНР. В рамках данного проекта китайские учёные выдвинули тезис о принадлежности истории государства Когурё истории Китая, что вызвало бурю протеста как в РК, так и в КНДР. ный период, и чья теория в немалой степени вобрала в себя элементы японской идеологии паназиатизма.

В 1980-е гг. псевдоисторики издали целый ряд сочинений, в том числе несколько переводов «Хвандан коги» с пояснениями. Кроме Древнего Чосона, который традиционно считается первым корейским государством, их сочинения посвящены изучению государств Хвангук (환국) - якобы общей прародине всех мировых цивилизаций - и Пэдаль (배달), считающемся прародиной культур Восточной Азии. Описывая более поздний период Трёх государств, псевдоисторики расширяют сферу их влияния далеко за пределы Корейского полуострова и южной части Маньчжурии, включая в неё значительную часть современной Японии, Китая и российского Приморья [17, c. 345].

Особый интерес в произведениях псевдоисториков вызывает интерпретация процесса этногенеза корейцев. Во-первых, в некоторых сочинениях корейцы объявляются избранным народом, носящим в своём нынешнем этнониме имя бога, так как «хан» (한) интерпретируется как производное от «ханыним» (하느님) [17, с. 356]. Во-вторых, стоит обратить внимание на этноним, которым называются протокорейцы - люди «пэдаль» - по названию государства, основанного Хвануном ${ }^{3}$. Пэдаль в свою очередь интерпретируется как «палк-ттан» (밝-땅; светлая земля), данное положение содержится также в теории Чхве Намсона о пульхамской культуре [17, с. 19]. В-третьих, прародиной корейцев называются окрестности Байкала - древней колыбели всего человечества [17, с. 25-26]. В-четвёртых, история корейского народа, по их мнению, насчитывает более 9 тыс. лет [17, с. 357].

Таким образом, согласно сочинениям псевдоисториков, корейский народ, являющийся богоизбранным, появился на просторах Азии более 9 тыс. лет назад из местности к востоку от озера Байкал, где и был расположен центр древнейшей человеческой цивилизации.

В 1990-е и 2000-е гг. активность псевдоисториков не только не ослабевает, но, напротив, возрастает в событиях, которые они сами называют не иначе, как «война за историю». Дело в том, что в конце 1980-х - начале 1990-х гг. китайские историки начали активно редактировать древнюю и средневековую историю регионов, некогда входивших в состав древних корейских государств. Это позволило псевдоисторикам объявить себя борцами с фальсификацией корейской истории [5, с. 6-11]. А последовавшая за этим в начале 2000-х гг. реализация Академией общественных наук КНР Северо-восточного проекта (동북공정 $)^{4}$ подвигла Сеул на ответные меры - так появился Фонд исследования истории Северо-Восточной Азии (동북아역 사재단), занимающийся созданием «правильной истории» СевероВосточной Азии. Такое внимание государства и общества к древней и средневековой истории Кореи не могло пройти мимо псевдоисториков, активно занимавшихся изучением именно этого периода корейской истории.

Появляются и новые переводы «Хвандан коги», сопровождающиеся не только переводом текста на современный корейский язык, но и пространными его разъяснениями со ссылками на археологические источники [5].

Из 19 обнаруженных через электронный каталог Библиотеки Национальной Ассамблеи РК переводов «Хвандан коги», 10 было из- 
дано после 2000 г., ещё 5 - после 1990 г. и 4 - в 1980-е гг. [7]. А на сайте крупнейшего в РК книжного магазина Кёбомунго можно заказать 35 книг, являющихся различными переводами «Хвандан коги» или отдельных её частей [6]. Среди таких переводов можно встретить не только полные или сокращённые (карманные) версии, но даже книги для детей [10]. То есть псевдоисторики не просто делают ставку на широкий круг читателей, а ориентируются на воспитание у подрастающего поколения нового понимания истории.

Бурное развитие оппозиционной исторической школы открыло двери её представителям в крупные университеты и позволило получить частное и государственное финансирование на исследовательские проекты, проведение конференций, издание книг и прочие мероприятия. В этой связи термин «неофициальная история», некогда применявшийся к её представителям, утратил свою актуальность, и вместо него появился новый - «псевдоисторики», которых в неофициальных разговорах иногда шутливо именуют «хванппа» (환빠), то есть «фанаты "Хван[дан коги]"».

Наиболее заметны псевдоисторики стали в 2014-2015 гг. после того, как под их влиянием Специальный комитет по противодействию искажению истории СВА (동북아역사왜곡대책특별위원회) Национальной Ассамблеи РК вынудил упомянутый выше Фонд истории СВА прекратить финансирование двух своих важных проектов реализуемого на базе Гарварда Early Korea Project (2006-2017 гг.) и корейского проекта электронного исторического атласа (2008-2015 гг.) $[4$, c. 38]. Одной из наиболее ярких иллюстраций влияния псевдоисториков на политическую элиту РК является факт цитирования «Хвандан коги» бывшим президентом Пак Кынхе в поздравительной речи по поводу годовщины освобождения Кореи 15 августа 2013 г. [8].

Одним из самых влиятельных псевдоисториков на сегодняшний день является Ли Догиль, руководящий своим частным Центром исследования истории и культуры «Хангарам» (한가람 역사문화 연구 소) [19]. Именно по его инициативе проходили обозначенные выше парламентские слушания. Согласно информации крупнейшего в РК книжного магазина Кёбомунго, Ли Догиль является автором многочисленных исторических произведений (на сайте было обнаружено 103 книги за его авторством) и ведёт авторскую колонку в одной из крупнейших газет РК - «Чосон ильбо». Кроме того, он имеет степень $\mathrm{PhD}$ (доктора философских наук), которую получил в 1998 г. на историческом факультете Университета Сунсиль [6].

Очень активно продвижением «Хвандан коги» в настоящий момент занимается религиозная организация Чынсандо (증산도, «Учение Чынсана»), являющаяся одной из так называемых «новых корейских религий». Последователи данного учения используют «Хвандан коги» в качестве религиозного текста, а нынешний патриарх Чынсандо - Ан Гёнчжон - является автором одного из переводов «Хвандан коги» на современный корейский язык. По мнению С. О. Курбанова, причина такой активности Ан Гёнчжона кроется в падении популярности Чынсандо в Корее, и его стремлении выйти на международную арену [2]. И, надо отдать Ан Гёнчжону должное, с этой задачей он успешно справляется, так как 20 февраля 2016 г. в Москве состоялась организованная Всемирной научной ассоциации Хвандан [коги] (세계환단 학회) Международная конференция по проблемам древней истории 
и культуры Кореи, на которой основным докладчиком выступил сам патриарх Чынсандо. К сожалению, в работе конференции приняли участие и ряд ведущих корееведов РФ, в некоторой степени легитимизировав всё на ней происходящее. По глубокому убеждению автора статьи, представителям академической науки стоит игнорировать подобные мероприятия, так как убедить сторонников «Хвандан коги» в том, что она сфальсифицирована, невозможно из-за природы их уверенности в её подлинности, которую можно описать словом «вера», то есть признание чего-либо истинным независимо фактического или логического обоснования. Полезным автору кажется научная критика работ псевдоисториков и широкое распространение этой критики вместе со сведениями об истории создания «Хвандан коги» как в академических кругах, так и среди обывателей.

\section{Литература}

1. Большой толковый словарь русского языка / Сост. и гл. ред. С. А. Кузнецов. СПб.: Норинт, 2000. 1536 с.

2. Курбанов С. О. Корейская религия чынсандо. Краткое изложение основных идейных постулатов. Личные впечатления. (Опыт многостороннего описания объекта.) // Вестник Центра Корейского Языка и Культуры. 2005. № 8. С. 218-239.

3. Хаврак А. П. Фальсификация истории и проблемы формирования патриотизма // Вестник экономической безопасности. 2016. № 1. С. 365-369.

4. Logie A. Diagnosing and Debunking Korean Pseudohistory // European Journal of Korean Studies. 2019. № 2. P. 37-80.

5. 계연수. 환단고기. - 대전: 상생출판 사, 2012. -320 쪽 = Ке Ёнсу. Древние записи [о временах царства] Хван[гук] и Тан[гуна]. - Тэчжон: Сансэнчхульпханса, 2012. $320 \mathrm{c}$.

6. 교보문고 (Книжный магазин Кёбо) [Электронный ресурc] URL: http://www. kyobobook.co.kr URL: http://dl.nanet.go.kr (Дата обращения: 22.10.2020).

7. 국회전자도서관 (Электронная библиотека Национальной Ассамблеи РК) [Электронный ресурc] URL: http://dl.nanet. go.kr (Дата обращения: 22.10.2020).

8. 박근혜 대통령 68 주년 광복절 경 축사 (Поздравительная речь президента Пак Кынхе [по поводу] 68 годовщины освобождения) [Электронный ресурс]. URL: https://www.mk.co.kr/news/politics/ view/2013/08/719845 (Дата обращения: 22.10.2020).
9. 세계환단학회 (Международное научное общество Хвандан) [Электронный pecypc] URL: http://www.hwandan.org (Дата обращения: 22.10.2020)

10. 안경전. (어린이) 환단고기. - 대전: 상생출판사, 2013. - 664쪽 $=$ Ан Гёнчжон. (Детская) [Летопись] «Хвандан коги». Тэчжон: Сансэнчхульпханса, 2013. 664 с.

11. 安東溭, 林承國. 韓國古代史學管 見. - 서울 : 景仁文化社, 1978. -227 兲 $=\mathrm{AH}$ Дончжун, Им Сынгук. Мнение о древней истории Кореи. - Сеул: Ёнинмынхваел, 1978. $227 \mathrm{c}$.

12. 안호상 (Ан Хосан) [Электронный pecypc] URL: http://100.daum.net/ encyclopedia/view/14XXE0035104 (Дата обращения: 22.10.2020).

13. 윤종영. 국사교과서 파동. - 서울: 혜안, 1999. - 342쪽 $=$ Юн Чонён. Кризис в учебниках по истории Кореи. - Сеул: Хеан, 1999. $343 \mathrm{c}$.

14. 이것이 한국고대사다 (1) «설화 조 사 혼동말아야》 // 경향신문. - 1978.11.17. 5 胥 $=$ Это древняя история Кореи (1) «не путайте легенды с реальной историей» // Газета «Кёнхян». 1978.11.17. С. 5.

15. 이문영. «환단고기》의 성립 배경과 기원(Ли Мунён. Истоки и контекст создания [летописи] «Хвандан коги») [Электронный ресурc] URL: http://www.ikaa. or.kr/webzine/read.php? pid=8\&id=99\&PHP SESSID=b3d9f1db5d7894d2c5b66c95d7d 18 6f0 (Дата обращения: 22.10.2020).

16. 이용범. 현대 한국의 단군 인식과 민족 문제 // 동북아 역사논총. - 2008. - № 20. - 53-84超 = Ли Ёнбом. Национальный 
вопрос и современное корейские восприятие Тангуна // Сборник по истории Северо-Восточной Азии. 2008. № 20. С. 53-84.

17. 임승국. 환단고기. - 서울: 정신세

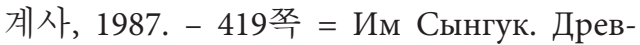
ние записи [о временах царства] Хан[гук] и Тан[гуна]. - Сеул: Чонсинсэгеса, 1987. $419 \mathrm{c}$.

18. 증산도 (Учение Чынсана) [Электронный ресурс] URL: http://www.jsd.or.kr
(Дата обращения: 22.10.2020).

19. 한가람역사문화연구소 (Центр исследования истории и культуры Хангарам) [Электр. pecypc] URL: http://www.historyin. org (Дата обращения: 22.10.2020).

20. 한국사. 권 $1-25$. 서울: 국사편 찬위원회, 1973 - 1979 = История Кореи.

Т. 1-25. - Сеул: Куксапхёнчханвивонхве. 1973-1979.

\title{
Vadim S. AKULENKO
}

Ph. D. (in History), Assistant Professor, Korean Studies Department, Oriental Institute - School of Regional and International Studies, Far Eastern Federal University (Vladivostok, Russia)

E-mail: akulenko.vs@dvfu.ru

\section{"Hwandan Kogi" and the Problem of History Falsification in the Republic of Korea}

\author{
UDC 94(519) \\ doi: dx.doi.org/10.24866/2542-1611/2020-3/6-14
}

The article is devoted to the problem of falsification of history in Hwandan kogi, the Republic of Korea using fabricated sources, a vivid example Korean history, of which is Hwandan Kogi". The research is based on various published versions of "Hwandan Kogi", as well as materials from the websites of the World Society of Hwandan History and Culture and the new Korean religion of Jeung San Do. In addition, the author analyzes several research articles in Russian, English and Korean

pseudo-history, unofficial history, falsification of history, Ancient Korea, Gojoseon

For citation: Akulenko V. S. "Hwandan Kogi" and the Problem of History Falsification in the Republic of Korea // Oriental Institute Journal. 2020. № 3. P. 6-14. doi: dx.doi.org/10.24866/2542-1611/2020-3/6-14

\section{References}

1. Bol'shoj tolkovyj slovar' russkogo yazyka / Sost. i gl. red. S. A. Kuznetsov. - SPb.: Norint, 2000. $1536 \mathrm{~s}$.

2. Kurbanov S. O. Korejskaya religiya chynsando. Kratkoe izlozhenie osnovnykh idejnykh postulatov. Lichnye vpechatleniya. (Opyt mnogostoronnego opisaniya ob"ekta.) // Vestnik TSentra Korejskogo YAzyka i Kul'tury. 2005. № 8. S. 218-239.

3. KHavrak A. P. Fal'sifikatsiya istorii i problemy formirovaniya patriotizma // Vestnik ehkonomicheskoj bezopasnosti. 2016. № 1. S. 365-369.

4. Logie A. Diagnosing and Debunking Korean Pseudohistory // European Journal of Korean Studies. 2019. № 2. P. 37-80.
5. 계연수. 환단고기. - 대전: 상 생출판사, 2012. - 320 쪽 $=\mathrm{Ke} \mathrm{YOnsu.}$ Drevnie zapisi [o vremenakh tsarstva] KHvan[guk] i Tan[guna]. - Tehchzhon: Sansehnchkhul'pkhansa, 2012.320 s.

6. 교보문고 (Knizhnyj magazin Kyobo) [EHlektronnyj resurs] URL: http://www. kyobobook.co.kr URL: http://dl.nanet.go.kr (Data obrashheniya: 22.10.2020).

7. 국회전자도서관 (EHlektronnaya biblioteka Natsional'noj Assamblei RK) [EHlektronnyj resurs] URL: http://dl.nanet. go.kr (Data obrashheniya: 22.10.2020).

8. 박근혜 대통령 68 주년 광복절 경 축사 (Pozdravitel'naya rech' prezidenta Pak Kynkhe [po povodu] 68 godovshhiny 
osvobozhdeniya) [EHlektronnyj resurs]. «Kyonkhyan». 1978.11.17. S. 5.

URL: https://www.mk.co.kr/news/politics/ 15. 이문영. «환단고기»의 성립 배경과 view/2013/08/719845 (Data obrashheniya: 기원(Li Munyon. Istoki i kontekst sozdaniya 22.10.2020).

9. 세계환단학회 (Mezhdunarodnoe nauchnoe obshhestvo KHvandan) [EHlektronnyj resurs] URL: http://www. hwandan.org (Data obrashheniya:22.10.2020). 10. 안경전. (어린이) 환단고기. - 대전: 상생출판사, 2013. -664 쪽 = An Gyonchzhon. (Detskaya) [Letopis'] «KHvandan kogi». Tehchzhon: Sansehnchkhul'pkhansa, 2013. $664 \mathrm{~s}$.

11. 安東濬, 林承國. 韓國古代史學管見. - 서울 : 景仁文化社, 1978. - 227 叒 $=A n$ Donchzhun, Im Synguk. Mnenie o drevnej istorii Korei. - Seul: YOninmynkhvael, 1978. $227 \mathrm{~s}$.

12. 안호상 (An KHosan) [EHlektronnyj resurs] URL: http://100.daum.net/ encyclopedia/view/14XXE0035104 (Data obrashheniya: 22.10.2020).

13. 윤종영. 국사교과서 파동.- 서울: 혜 안, 1999. - 342쪽 = YUn CHonyon. Krizis v uchebnikakh po istorii Korei. - Seul: KHean, 1999. $343 \mathrm{~s}$.

14. 이것이 한국고대사다 (1) «설화 조 사 혼동말아야》// 경향신문. - 1978.11.17. 5 쪽 = EHto drevnyaya istoriya Korei (1) «ne putajte legendy s real'noj istoriej» // Gazeta [letopisi] «KHvandan kogi») [EHlektronnyj resurs] URL: http://www.ikaa.or.kr/webzine/ read.php? pid $=8 \& \mathrm{id}=99 \&$ PHPSESSID $=\mathrm{b} 3$ d9f1db5d7894d2c5b66c95d7d186f0 (Data obrashheniya: 22.10.2020).

16. 이용범. 현 대 한국의 단군 인식과 민 족 문제 // 동북아 역사논총. - 2008. - № 20. -53-84쪽 = Li YOnbom. Natsional'nyj vopros i sovremennoe korejskie vospriyatie Tanguna // Sbornik po istorii Severo-Vostochnoj Azii. 2008. № 20. S. 53-84.

17. 임승국. 환단고기. - 서울: 정신세 계사, 1987. - 419쪽 = Im Synguk. Drevnie zapisi [o vremenakh tsarstva] KHan[guk] i Tan[guna]. - Seul: CHonsinsehgesa, 1987. 419 s.

18. 증산도 (Uchenie CHynsana) [EHlektronnyj resurs] URL: http://www.jsd. or.kr (Data obrashheniya: 22.10.2020).

19. 한가람역사문화연구소 (TSentr issledovaniya istorii i kul'tury KHangaram) [EHlektr. resurs] URL: http://www.historyin. org (Data obrashheniya: 22.10.2020).

20. 한국사. 권 $1-25$ - 서울: 국사편찬 위원회, 1973 - 1979 = Istoriya Korei. T. 1-25. - Seul: Kuksapkhyonchkhanvivonkhve. 19731979. 